\title{
Modal Analysis of Axially Symmetric Structure
}

\author{
Pavol Lengvarský*, Martin Hagara, Martin Schrötter, Jozef Bocko \\ Department of Applied Mechanics and Mechanical Engineering, Technical University of Košice, Faculty of Mechanical Engineering, Slovakia \\ *Corresponding author: pavol.lengvarsky@tuke.sk
}

Received October 16, 2014; Revised October 22, 2014; Accepted November 07, 2014

\begin{abstract}
There is described the identification of coupled modes of axially symmetric structure in this paper. The stiff pipe with free-free boundary conditions was chosen as an investigated specimen. Two different experimental modal analysis approaches were performed and their results were compared with numerical methods.
\end{abstract}

Keywords: experimental modal analysis, coupled modes, axially symmetric structure

Cite This Article: Pavol Lengvarský, Martin Hagara, Martin Schrötter, and Jozef Bocko, "Modal Analysis of Axially Symmetric Structure.” American Journal of Mechanical Engineering, vol. 2, no. 7 (2014): 265-269. doi: 10.12691/ajme-2-7-19.

\section{Introduction}

Currently, modal analysis as a tool for investigation of vibration becomes an important part of designer work. Whether it is necessary to perform determination of modal parameters, analyze amplitudes of vibration [1,2], verify the numerical model experimentally [3,4] or express the influence of different parameters on the vibration $[5,6]$, the knowledge of dynamic behavior of structures plays an important role as they are designed.

For bodies that are shape symmetric and their mass is symmetrically distributed along their volume at the same time the mode shapes are also symmetric. From theoretical point of view it is valid for such types of bodies that at the same frequency can present more modes. These modes, which are called multiple or coupled, have identical natural frequencies and damping and differ in mode shapes which are mutually rotated about the body's axis of symmetry.

For real bodies there is some frequency shift of these modes, which depends on symmetry accuracy of given body. Not all methods of modal analysis are convenient for identification of coupled modes [7]. On the basis of measured frequency response functions (FRFs) it is not possible to predict coupled modes by the reason of their insufficient frequency resolution.

Rational fraction polynomial (RFP) method is MDOF method which works in frequency domain. This method is based on curve fitting and essence of this method is that each FRF can be expressed as a ratio of polynomials. Poles (roots of FRF's denominator) express the system modal characteristic.

Complex mode indicator function (CMIF), which algorithm is based on singular value decomposition (SVD), is very suitable method for an identification of coupled modes. This method enables to find the real as well as the complex modes, their relative magnitudes and also to plot their mode shapes.
Frequency domain decomposition (FDD) method is mode estimation method predominantly used in operational modal analysis. It uses SVD of spectral matrix which is decomposed into a set of auto spectral density functions. This is valid only for cases when the structure is lightly damped and excited with white noise.

\section{Description of the Experiment}

The steel pipe with free-free boundary conditions was used in the experiment in order to identify the coupled modes (Figure 1).

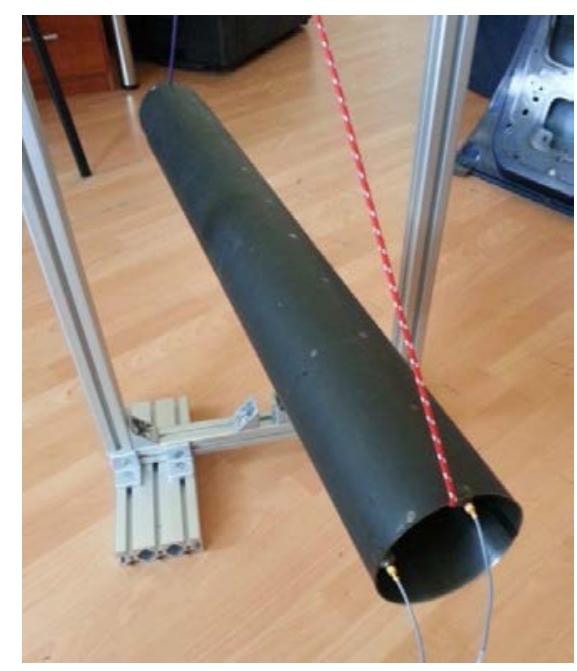

Figure 1. The process of coupled modes investigation by EMA

Measuring devices used during the experiment:

- 6-channel measuring device Brüel\&Kjaer - PULSE,

- uniaxial accelerometers Brüel\&Kjaer, type 4507-B,

- modal hammer Brüel\&Kjaer, type 8206 with plastic tip.

Accelerometers were attached to pipe using bee wax. Their orientation and localization by experimental modal analysis method (EMA) is depicted in Figure 2 and by operational modal analysis (OMA) in Figure 3. 


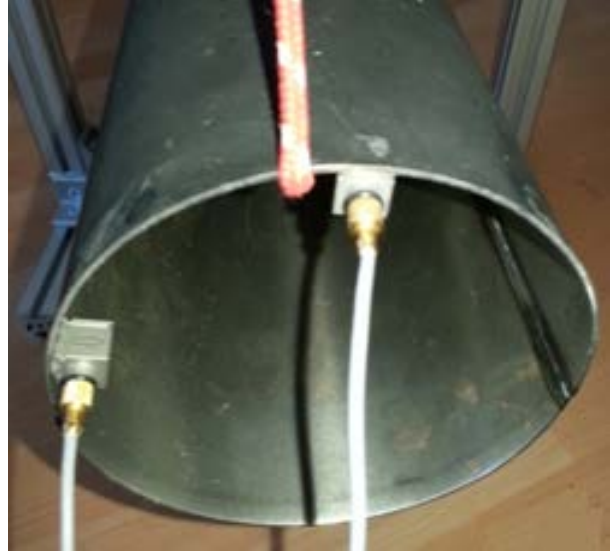

Figure 2. Details of localization of accelerometers by EMA method

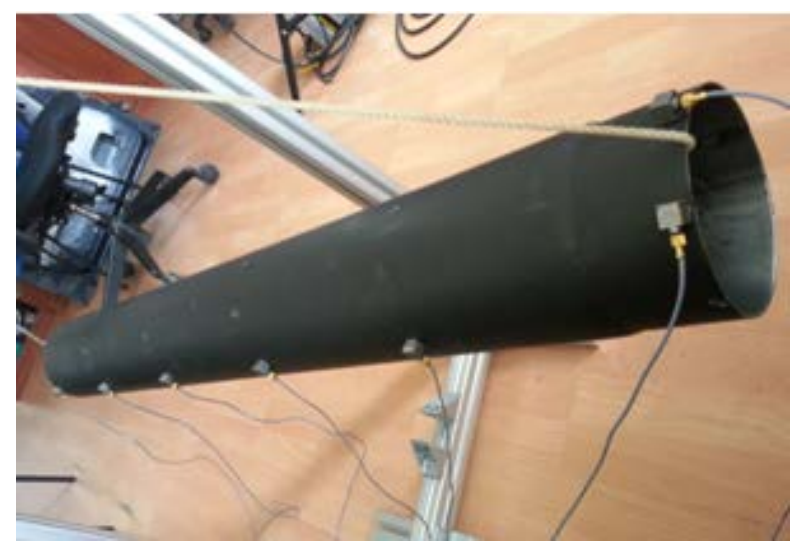

Figure 3. Details of localization of accelerometers by OMA method

\section{Realization of Measurement by Experimental Modal Analysis Method}

The pipe geometry was created in MTC-Hammer program by 88 points ( 8 points lay on the circumference and 11 along the pipe's length). Investigated frequency range was set with up span $0-1600 \mathrm{~Hz}$ with frequency accuracy $1 \mathrm{~Hz}$. By measurement we received 88 FRFs which were needed, in order to further processing, to import to REFLEX program. The CMIF function (Figure 4) and averaged FRF function (Figure 5) were depicted from gained data.

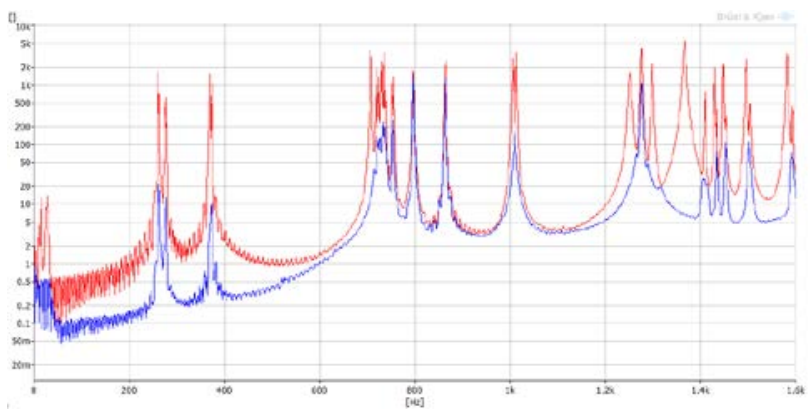

Figure 4. CMIF function of investigated pipe

On the basis of course of FRF, CMIF and also on the basis of phase shifts it is possible to determine approximately the modes of investigated body. For their accurate identification it is necessary to apply some modal parameters estimation method.
The most convenient method of modal parameters estimation available in REFLEX program, for instance of coupled modes, is on the basis of the rational fraction polynomial method, which uses stability diagram.

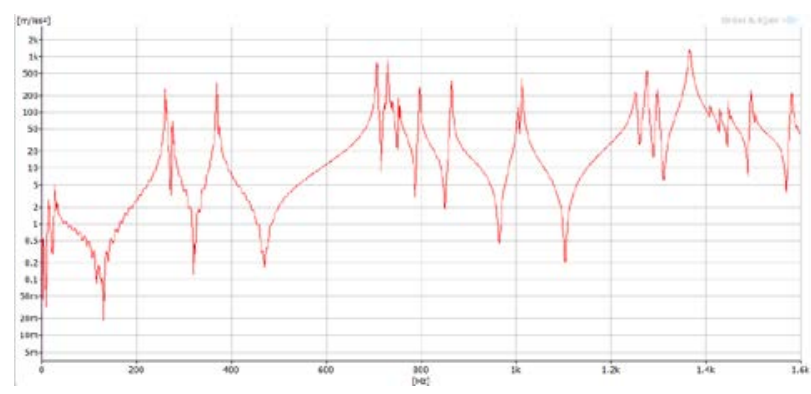

Figure 5. Averaged FRF function of investigated pipe

\section{Realisation of Measurement by Operational Modal Analysis Method}

In this measurement the pipe geometry, initially created in MTC-Hammer program, was exported to OMAAnalysis program. The setting of analyzer frequency span was also the same as was in former experiment. Stochastic excitation was realized with modal hammer because of its known frequency span excitation and also in order to retain broadband of excitation [8]. There were used seven accelerometers in OMA measurement, where one was reference, in contrast to EMA measurement where two accelerometers were used. Fifteenth sets of data were measured at all whereby time of measurement of each set was 13 seconds. The pipe modes were determined by frequency domain decomposition method. The course of singular lines and localizations of estimated modes are depicted in Figure 6. The noise can be separated from real signal by decomposition of singular values so the modes can be easily determined from the peaks of depicted singular values.

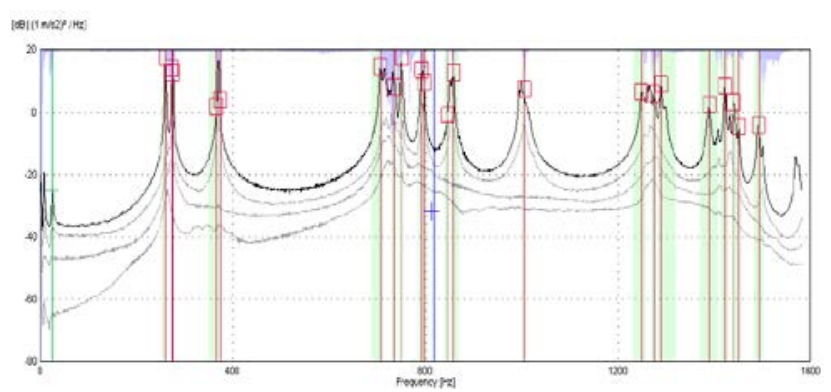

Figure 6. Modes estimation by SVD decomposition in frequency domain

The comparison of investigated pipe natural frequencies, obtained by FEM, OMA and EMA, is depicted in Table 1 and also there are presented values of damping ratio $\zeta[\%]$ on particular frequencies, obtained by experimental modal analysis method.

Modes in Table 1 are sorted increasingly from mode no. 1 to mode no. 10. The symbols $a, b$ represent coupled modes.

Coupled fifth mode (bending) was not found by EMA method because of used accelerometer localization. The considerable accordance of natural frequencies values can be seen from measured data. Natural frequencies obtained by experimental and operational modal analysis 
are in any cases lower than those obtained by finite element method (by SolidWorks). This frequency difference is caused by exclusion of damping in simulation by SolidWorks and also by some weight of accelerometers. The weight difference was not so distinct to considerably influent natural frequencies by EMA and OMA. Their difference is rather caused by other forms of excitation and especially by other computational method.

\begin{tabular}{|c|c|c|c|c|c|}
\hline & & \multicolumn{4}{|c|}{ Frequency of particular mode [Hz] } \\
\hline & mode & 1. a & 1. b & 2. a & 2. b \\
\hline \multirow{4}{*}{ 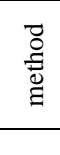 } & FEM & 279,08 & 279,08 & 290,36 & 290,36 \\
\hline & OMA & 260,1 & & 273,6 & 275,2 \\
\hline & EMA & 260,05 & 262,06 & 274,04 & 275,16 \\
\hline & $\zeta[\%]$ & 0,174 & 0,166 & 0,169 & 0,179 \\
\hline
\end{tabular}

\begin{tabular}{|c|c|c|c|c|c|}
\hline & & \multicolumn{4}{|c|}{ Frequency of particular mode $[\mathrm{Hz}]$} \\
\hline & mode & 3.a & 3.b & 4.a & 4.b \\
\hline \multirow{3}{*}{ 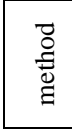 } & FEM & 381,17 & 381,17 & 713,55 & 713,55 \\
\hline & OMA & 365,6 & 368,2 & 706,1 & 712,9 \\
\hline & EMA & 368,09 & 369,46 & 705,42 & 714,05 \\
\hline & $\zeta[\%]$ & 0,126 & 0,148 & 0,136 & 0,117 \\
\hline
\end{tabular}

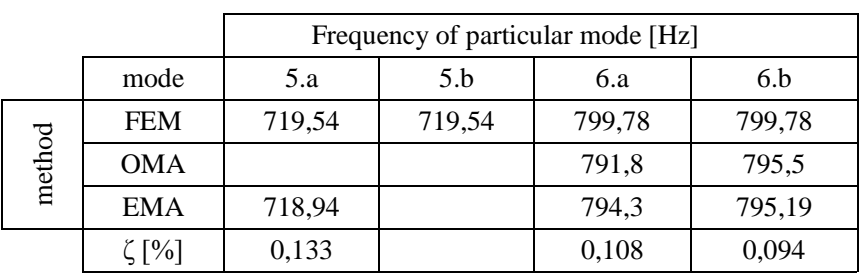

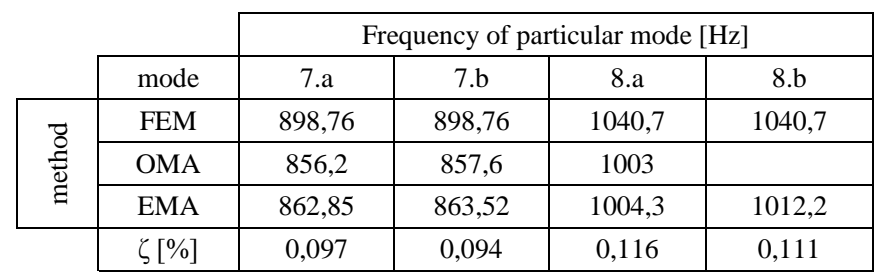

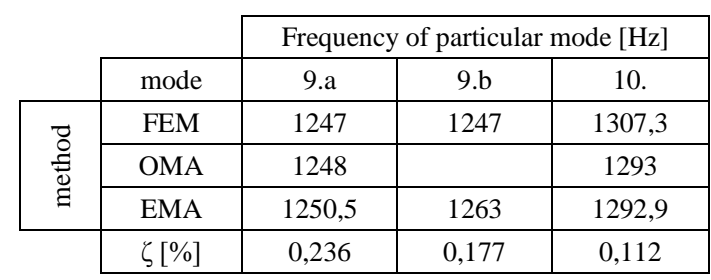

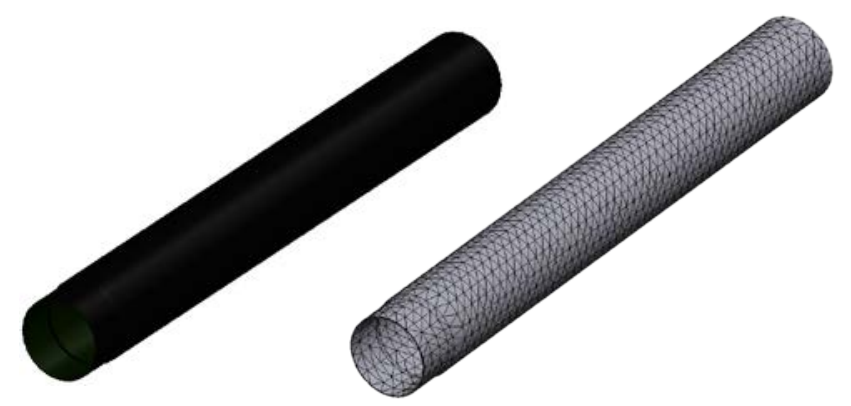

Figure 7. Model of pipe and finite element mesh in SolidWorks

In Figure 7 is given the finite element mesh created in SolidWorks. This mesh composes of spatial element SOLID187. The element is defined by 10 nodes while each node has three degrees of freedom. The SOLID187 has a quadratic shifting behavior and is suitable for modelling of the finite element irregular mesh.

The mesh is created of 7300 elements and of 14727 nodes.

There are presented pipe's mode shapes obtained by EMA and FEM methods in (Figure 8 - Figure 18).

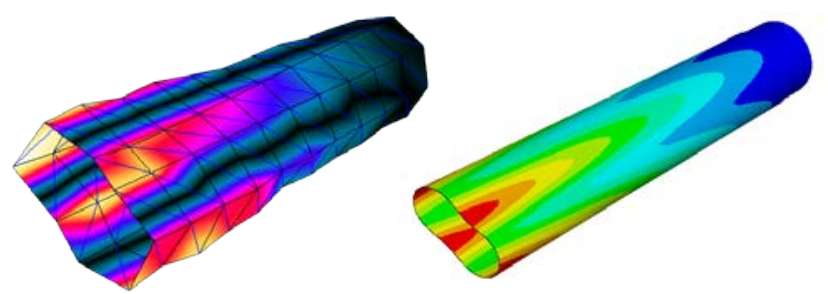

Figure 8. The first mode shape by EMA/FEM
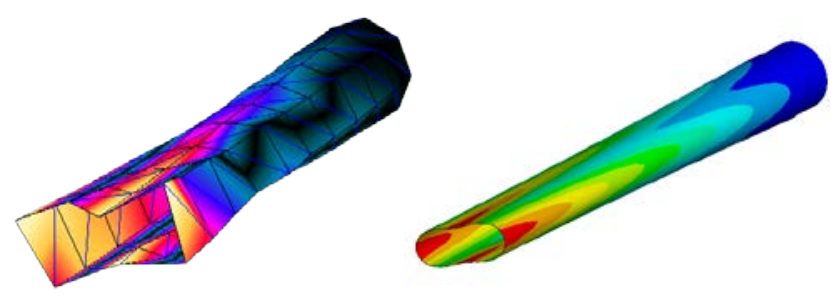

Figure 9. The first coupled mode shape by EMA/FEM

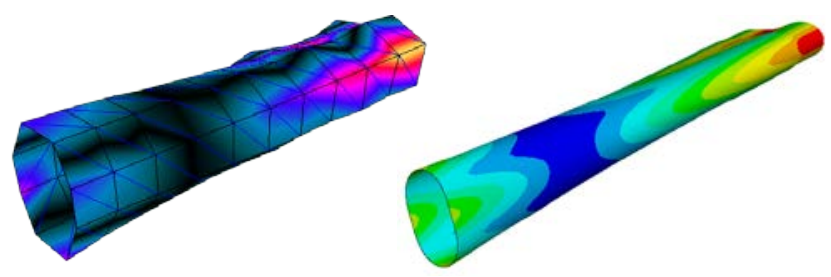

Figure 10. The second mode shape by EMA/FEM
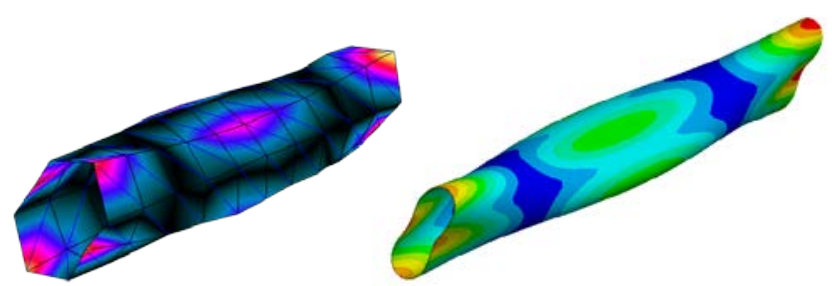

Figure 11. The third mode shape by EMA/FEM

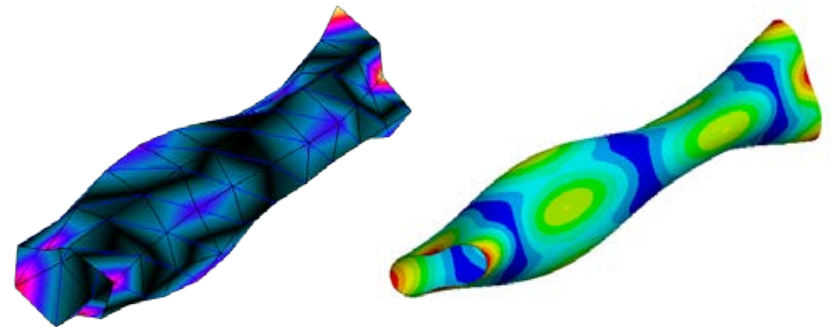

Figure 12. The fourth mode shape by EMA/FEM

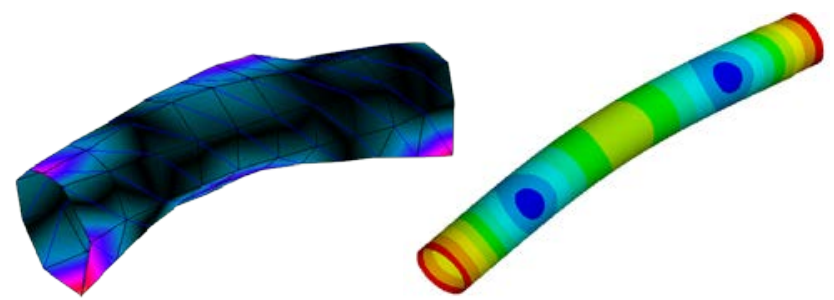

Figure 13. The fifth mode shape by EMA/FEM 


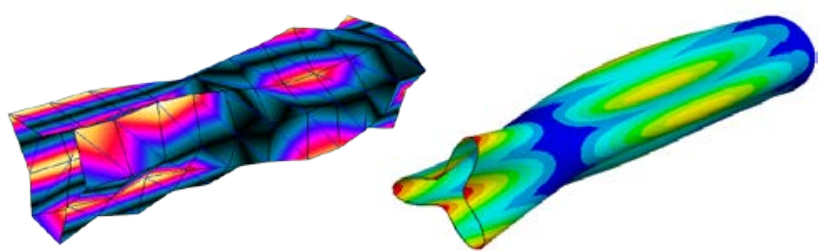

Figure 14. The sixth mode shape by EMA/FEM

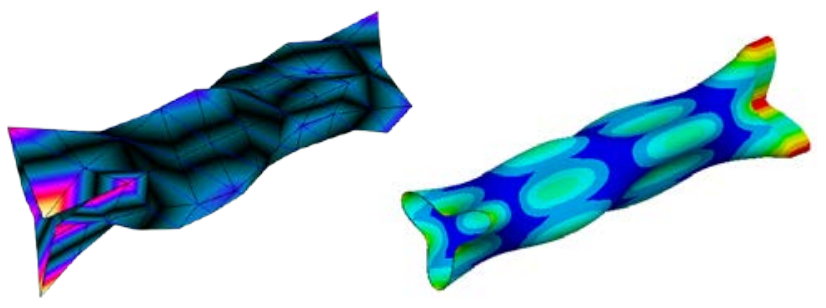

Figure 15. The seventh mode shape by EMA/FEM

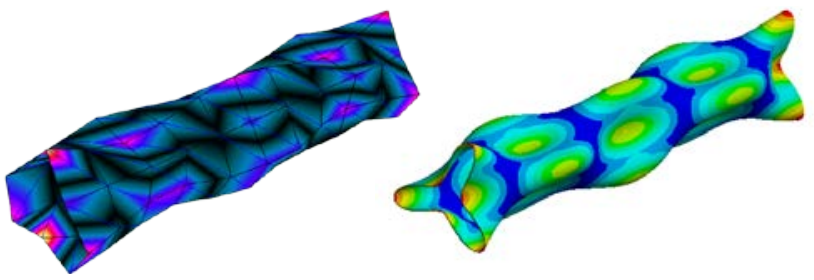

Figure 16. The eighth mode shape by EMA/FEM

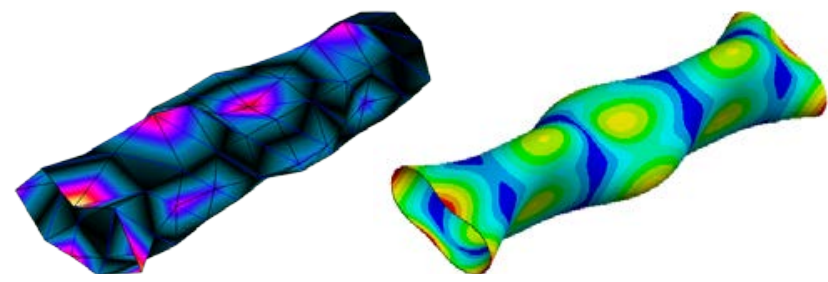

Figure 17. The ninth mode shape by EMA/FEM

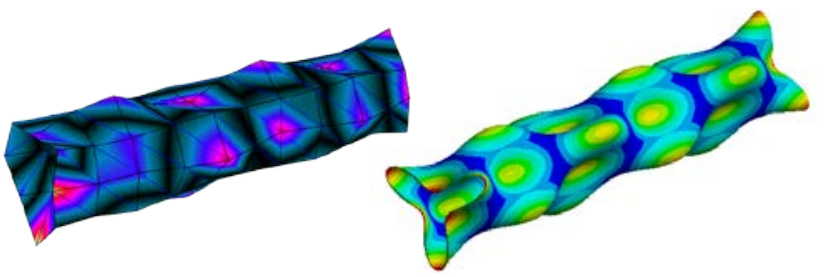

Figure 18. The tenth mode shape by EMA/FEM
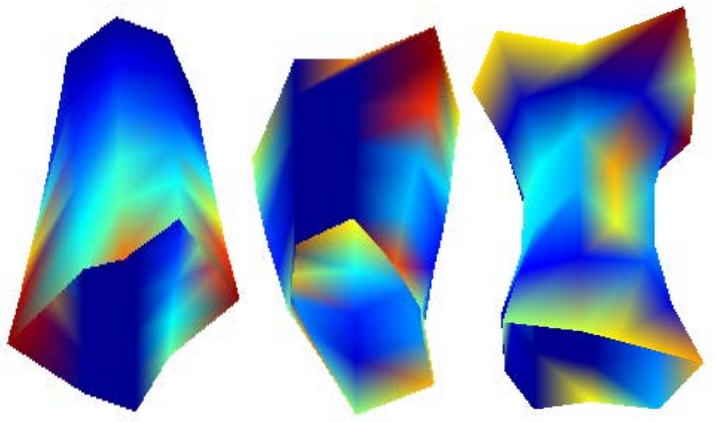

Figure 19. The First, the second and the third pipe's mode shape obtained by OMA

There is presented coupled mode shape of first mode in Figure 9. Other coupled mode shapes are depicted in Figure 20 - Figure 23. Mode shapes obtained by operational modal analysis method were depicted only for first three modes because of low visualization ability of used program (Figure 19).

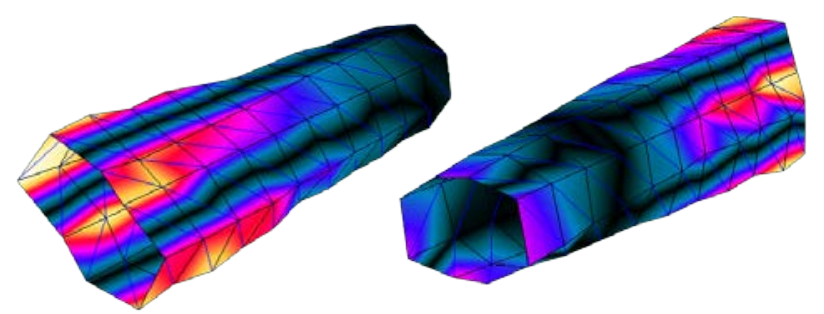

Figure 20. The first and the second coupled mode shape

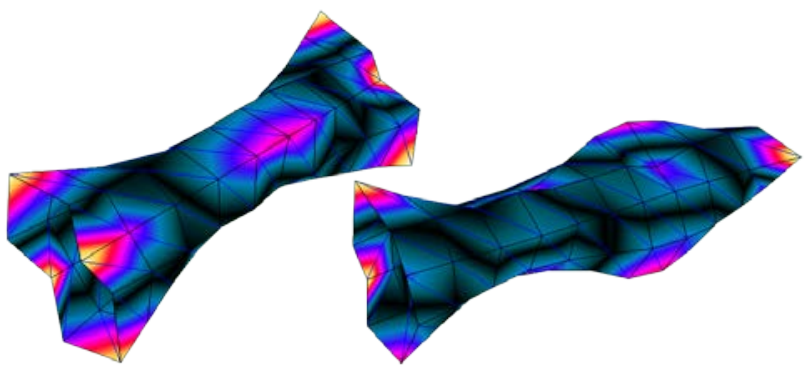

Figure 21. The third and the fourth coupled mode shape

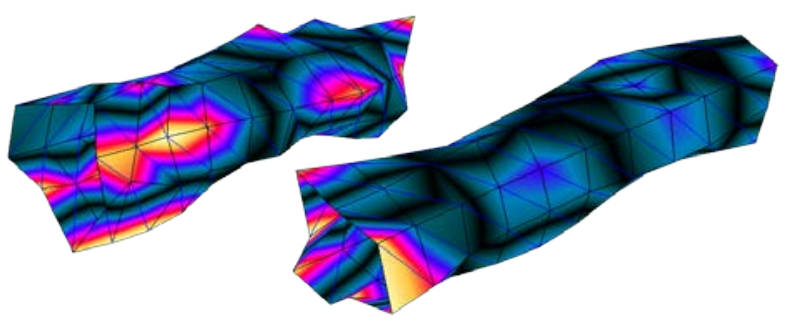

Figure 22. The sixth and the seventh coupled mode shape

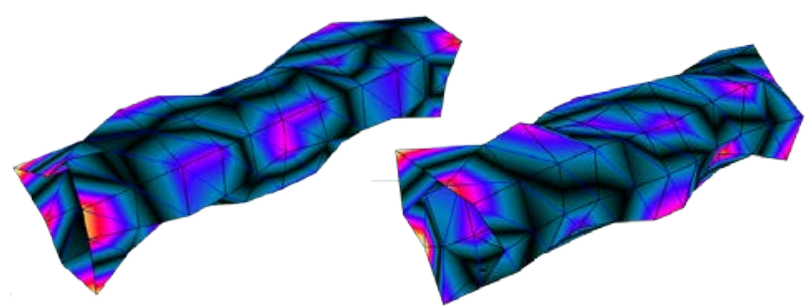

Figure 23. The eighth and the ninth coupled mode shape

\section{Conclusion}

The aim of the paper was to mention the possibilities of using modern methods of modal analysis by the investigation of dynamic characteristics of mechanical systems. The performed measurement deals with the determination of coupled modes of axially symmetric structure. Using convenient methods of modal parameters estimation the mode shapes and natural frequencies of first 9 modes were achieved.

\section{Acknowledgement}

This article was created with support of VEGA grant projects VEGA 1/1205/12 Numerical modelling of mechatronic systems and VEGA 1/0937/12 
The development of non-traditional experimental methods for mechanical and mechatronic systems.

\section{References}

[1] Trebuňa F., Šimčák F., Huňady R.: Experimental vibration analysis of railcar for spent nuclear fuel transportation. American Journal of Mechanical Engineering, Vol. 1, no. 7 (2013), pp 423426.

[2] Svoboda M., Soukup J.: Dynamic Measurement of Four-Axle Railway Wagon. Manufacturing Technology, Vol. 13, no. 4 (2013), pp 552-558.

[3] Yang Y. W. et al.: Experimental and Numerical Modal Analysis of Gearbox Casing in a Polishing Machinery. Advanced Materials Research, Vol. 69-70 (2009), pp 560-564.
[4] Svoboda M., Soukup J.: Verification of Numeric Solution by Experiment for Examination Vertical Oscillation of a Mechanical System. Manufacturing Technology, Vol. 13, no. 4 (2013) pp 559563.

[5] Hagara M., Schrötter M., Lengvarský P.: An investigation of the temperature influence on a shift of natural frequencies using digital image correlation. Applied Mechanics and Materials, Vol. 611 (2014), pp 506-510.

[6] Svoboda M., Soukup J.: The Influence of Geometry, Manufacturing Asymmetry and Asymmetric Excitation on Vertical Vibration of a Mechanical System. Applied Mechanics and Materials, Vol. 302 (2013), pp 429-434.

[7] Schwarz B., Richardson M.: Experimental modal analysis, Jamestown, California, 1997.

[8] Trebuňa F., Šimčák F., Huňady R.: Kmitanie a modálna analýza mechanických sústav. Košice, 2012. 